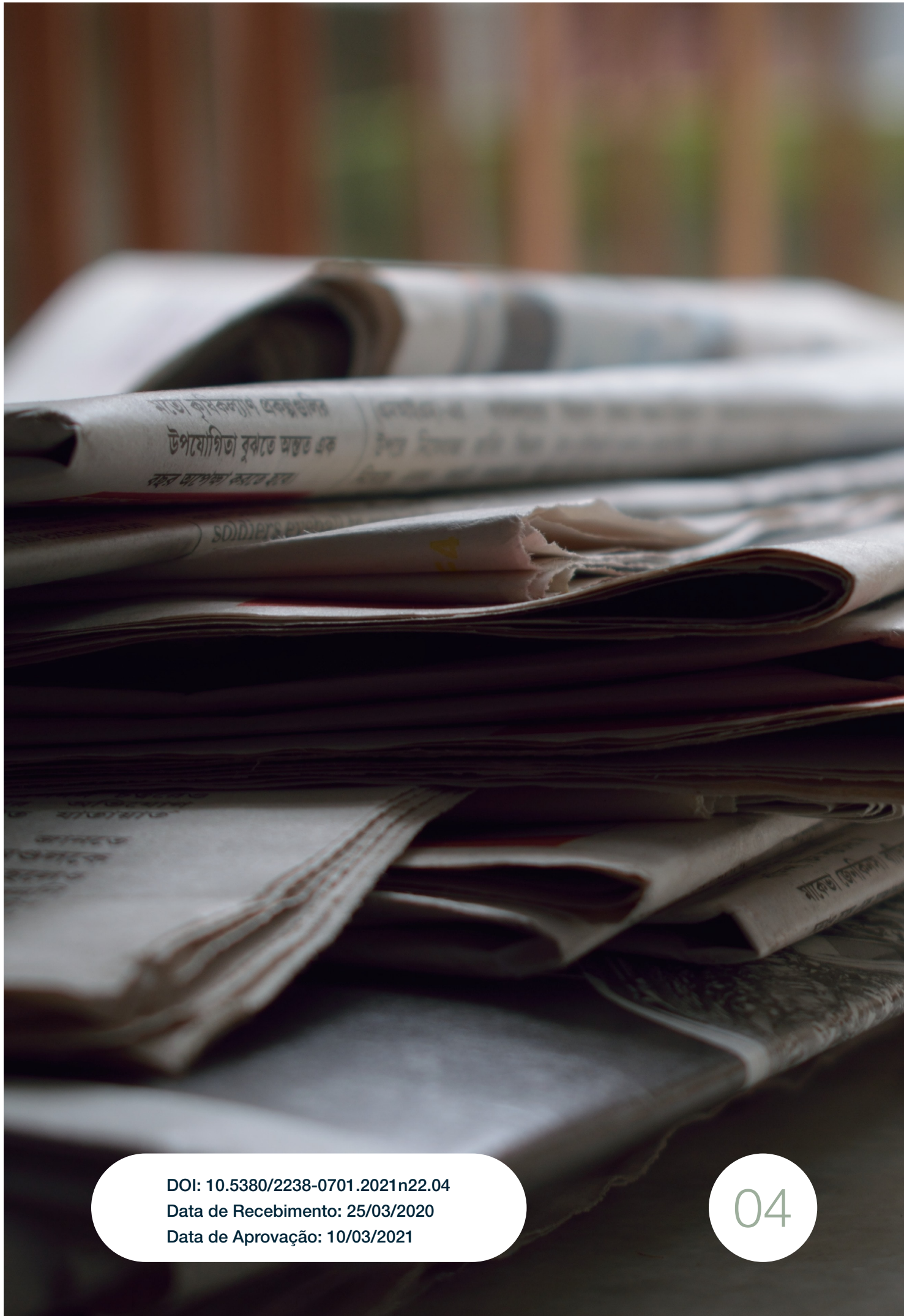


Quando o jornalismo legitima uma identidade como hegemônica: Silenciamentos, Oktoberfest e imprensa em Blumenau 


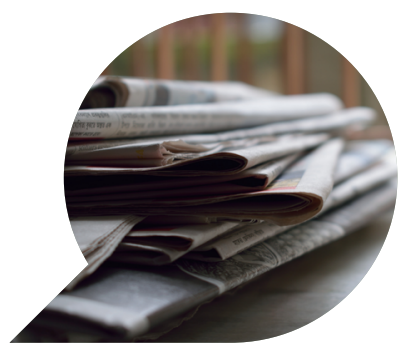

\section{Quando o jornalismo legitima uma identidade como hegemônica: Silenciamentos, Oktoberfest e imprensa em Blumenau}

When journalism legitimizes an identity as hegemonic:

Silences, Oktoberfest and the press in Blumenau

Cuando el periodismo legitima una identidad como hegemónica: Silencios, Oktoberfest y la prensa en Blumenau

\begin{tabular}{c}
\hline JORGE KANEHIDE IJUIM ${ }^{1}$ \\
\hline MAGALI MOSER \\
\hline
\end{tabular}

Resumo: Este artigo busca compreender o papel do jornalismo na construção identitária que faz o município catarinense de Blumenau ser reconhecido pelo rótulo de "Alemanha Brasileira", com base na Oktoberfest. A imagem dominante disseminada pelos meios de comunicação alcança uma visão homogênea sobre o chamado "Vale Europeu", promovendo a ideia de um "Sul do Brasil" distinto de outras regiões do país, pois europeizado. Entretanto, as produções discursivas sobre a região, assim como sua identidade, apresentam-se em disputa. Vozes dissonantes questionam a narrativa

1 Doutor em Ciências da Comunicação/Jornalismo pela Escola de Comunicações e Artes da USP, pós-doutor pela Universidade de Coimbra (Portugal); professor de graduação e pós-graduação na Universidade Federal de Santa Catarina.

2 Jornalista; mestra em Jornalismo pela UFSC; doutoranda no Programa de Pós-graduação em Jornalismo da UFSC. 
predominante e evidenciam a existência de uma contraditória narrativa hegemônica sobre a identidade de Blumenau. Neste confronto simbólico, o objetivo da pesquisa foi avaliar o comportamento da imprensa e entender os porquês de tal posição, sendo o Jornal de Santa Catarina (JSC) o objeto empírico da análise, escolhido como narrador principal. Um estudo exploratório, baseado na análise de conteúdo, definiu como corpus do trabalho 30 reportagens publicadas num intervalo de 31 anos da festa, de 1984 a 2015. Além disso, incluiu ainda a produção de 23 entrevistas a partir de vozes amplificadoras da germanidade e questionadoras do imaginário hegemônico. Os procedimentos metodológicos se ampararam na análise crítica da narrativa (MOTTA, 2013) e em entrevistas em profundidade (DUARTE, 2006).

Palavras-chave: Jornalismo e Sociedade, Identidade Cultural, Germanidade, Oktoberfest e Blumenau.

Abstract: This article seeks to understand the role of journalism in the identity construction that makes the Santa Catarina municipality of Blumenau recognized by the label of "Brazilian Germany", based on Oktoberfest. The dominant image disseminated by the media reaches a homogeneous vision of the so-called "European Valley", promoting the idea of a "South of Brazil" distinct from other regions of the country, as it is Europeanized. However, the discursive production about the region, as well as its identity, is in dispute. Dissonant voices question the predominant narrative and show the existence of a contradictory hegemonic narrative about Blumenau's identity. In this symbolic confrontation, the objective of the research was to assess the behavior of the press and understand the reasons for such a position, with Jornal de Santa Catarina (JSC) being the empirical object of the analysis, chosen as the main narrator. An exploratory study, based on content analysis, defined as corpus of the work 30 reports published in an interval of 31 years of the party, from 1984 to 2015. In addition, it also included the production of 23 interviews based on German amplifying and questioning voices of the hegemonic imaginary. The methodological procedures were supported by the critical analysis of the narrative (MOTTA, 2013) and in-depth interviews (DUARTE, 2006).

Keywords: Journalism and Society, Cultural Identity, Germanity, Oktoberfest and Blumenau. 
Resumen: Este artículo busca comprender el papel del periodismo en la construcción de identidad que hace que el municipio de Blumenau, en Santa Catarina, sea reconocido con la etiqueta "Alemania Alemania", basada en el Oktoberfest. La imagen dominante difundida por los medios de comunicación alcanza una visión homogénea del llamado "Valle Europeo", promoviendo la idea de un "Sur de Brasil" distinto de otras regiones del país, por estar europeizado. Sin embargo, la producción discursiva sobre la región, así como su identidad, está en disputa. Voces disonantes cuestionan la narrativa predominante y muestran la existencia de una narrativa hegemónica contradictoria sobre la identidad de Blumenau. En este enfrentamiento simbólico, el objetivo de la investigación fue evaluar el comportamiento de la prensa y comprender las razones de tal posición, siendo el Jornal de Santa Catarina (JSC) el objeto empírico del análisis, elegido como narrador principal. Un estudio exploratorio, basado en análisis de contenido, definió como corpus del trabajo 30 informes publicados en un intervalo de 31 años de la fiesta, de 1984 a 2015. Además, también incluyó la producción de 23 entrevistas basadas en amplificación y cuestionamiento alemán voces del imaginario hegemónico. Los procedimientos metodológicos se apoyaron en el análisis crítico de la narrativa (MOTTA, 2013) y entrevistas en profundidad (DUARTE, 2006).

Palabras clave: Periodismo y Sociedad, Identidad Cultural, Germanidad, Oktoberfest y Blumenau.

\section{Introdução}

A ampla repercussão e a visibilidade alcançada em torno do produto Oktoberfest parecem aprisionar o município de Blumenau (SC) a um passado remoto e questionável, mas apresentado predominantemente como homogêneo nas narrativas jornalísticas. Na produção discursiva sobre o município, em diferentes esferas, a exaltação das heranças alemãs costuma apagar o reconhecimento de sua diversidade cultural e étnica. Ao reduzir as múltiplas identidades de Blumenau à germanidade, a imprensa muitas vezes reforça uma suposta superioridade alemã baseada na desqualificação do Outro, entendendo-o aqui como aquele que não reuniria características desta etnicidade. A pretensa harmonia 
na representação majoritária de Blumenau esconde relações de poder (FOUCAULT, 1986) entre diversas forças, manifestadas pela preocupação em manter o verniz dessas aparências e movimentos contrários que as contestam e problematizam. A partir desta imagem forjada, há disputas, tensões e conflitos ocultados pela narrativa dominante. A proposta aqui se centra na análise do jornalismo como não o único, mas um dos agentes desta produção de sentidos ${ }^{3}$.

Entre os fatores da distorção acerca da representação de Blumenau está o fato de a cidade celebrar a cultura e a tradição de um fragmento da Alemanha, distante da sua própria história e capaz de impor um sentido quase único de si mesma. A principal celebração do germanocentrismo no município aparenta o desejo de reproduzir hábitos de uma região específica da Alemanha, no caso o Sul (Baviera), onde ocorre a Festa da Cerveja de Munique. O fundador da Colônia Blumenau, Hermann Bruno Otto Blumenau, veio de Braunschweig, (Centro Norte da atual Alemanha), e a maioria dos imigrantes, da Saxônia. Poucos teriam vindo do Sul, pois reinos como o da Baviera eram prósperos e não havia razão para emigrar (VOIGT, 1999). Essa seletividade das inspirações para germanizar Blumenau diz muito do caráter fabricado da invenção de suas tradições e do esforço em estabelecer essas relações como algo dado, autêntico irrefutável e naturalizado.

Blumenau reproduz a atmosfera de uma parte da Alemanha como se todo o país que admira fosse aos mesmos moldes. A cobertura jornalística durante a festa de outubro costuma apagar diferenças na unificação de um discurso e negação de vários outros. Apesar da discrepância histórica, a Oktoberfest aparece na imprensa como retrato "genuíno" de expressão da cultura local e celebração dos colonizadores "alemães". Mesmo que a constituição do Estado moderno alemão (o país, Alemanha) tenha se dado apenas em 1871, a Colônia Blumenau (1850) inicia antes da própria existência da Alemanha como país, mas isso nunca é lembrado pelos relatos epopeicos reproduzidos pela mídia, já que desvendaria o quão anacrônico é ver uma colônia alemã antes mesmo de a Alemanha existir. "Assim, quando aqui chegaram, estes imigrantes eram prussianos, bávaros, renanos, mas ainda não podiam ser considerados alemães" (FLORES, 1997, p. 48).

3 Este artigo apresenta resultados parciais da dissertação Jornalismo Forjado: A participação da imprensa na imposição da identidade germânica em Blumenau (MOSER, 2016). 
O ponto de partida da pesquisa foi o Jornal de Santa Catarina (JSC), único diário de Blumenau, lançado por um grupo de empresários em 1971, vendido para a Rede Brasil Sul (RBS) em 1992 e, novamente, para o grupo NC em fevereiro de 2016 (depois renomeada NSC). O estudo baseou-se num corpus composto por 30 reportagens, publicadas no periódico entre 1984, quando a festa foi lançada, e 2015, permitindo um olhar panorâmico abrangente sobre esta construção. Materiais de outros veículos complementaram a pesquisa, dialogando com o corpus principal. Por este motivo, não foram ignorados, como prevê a metodologia da análise crítica da narrativa, adotada aqui. O objetivo foi perceber como se dá a disputa pela narrativa oficial em torno do município e buscar reflexões na tentativa de desvendar os porquês do comportamento assumido pela imprensa. Como objetivos específicos, buscamos relativizar a naturalização da narrativa hegemônica, confrontar as noções de jornalismo e identidades, além de identificar as vozes que reforçam e contrapõem a narrativa hegemônica.

Desde sua fundação, em 1971, o JSC - sigla do jornal analisado - tem reivindicado a posição de uma espécie de "porta-voz" da comunidade local. No entanto, seria um erro estudá-lo de forma isolada. O JSC assume esta bandeira desde o nascimento, como o principal periódico de Blumenau e região. Seu primeiro editorial levantava a necessidade da busca pela unidade catarinense e superação de barreiras históricas, desejo dos seus diretores. Reproduzimos um trecho emblemático: "[...] não mediremos esforços para promover a integração e a união deste Estado de Santa Catarina (EDITORIAL, 22 de setembro de 1971, p. 2). O próprio nome do Estado catarinense no jornal teria papel na integração. Mas o uso de estratégias de legitimação do discurso oficial da identidade está para além do veículo: é uma prática generalizada, como sinalizou a pesquisa. Por isso, a busca aqui foi pela compreensão do fazer jornalístico, sem descartar o contexto histórico, social e político no qual o periódico está inserido, na tentativa de contribuir para o melhor entendimento sobre a complexidade do fenômeno. 


\section{"Loira Blumenau": A construção de uma farsa}

Enchentes, sotaque alemão e Oktoberfest constroem o imaginário coletivo de Blumenau. Localizada numa das áreas consideradas mais desenvolvidas de Santa Catarina, a região batizada de Vale Europeu pelo setor turístico é apresentada em narrativas jornalísticas nacionais como "campeã em qualidade de vida" e "paraíso dos brasileiros"4. Tornou-se símbolo de "um Brasil que deu certo" tes sociais, tal como a costumeira representação do enfrentamento às cheias, que marcam sua trajetória desde a fundação. Mas as imagens do município tomada pelas águas, com o transbordamento do Rio Itajaí Açu, acompanham-na como os discursos associados às tradições germânicas. Os desastres aparecem inclusive como reforço à capacidade de superação do povo blumenauense. No processo de legitimação identitária do município, a germanidade parece ter assumido ainda mais força com as enchentes dos anos 1980.

Os discursos sobre Blumenau ajudaram a construir uma identidade forjada na concepção de "cidade eficiente" e de um "povo trabalhador", acostumado a arregaçar as mangas, limpar com rapidez a lama deixada pelas cheias e superar com alegria quaisquer adversidades (FROTSCHER, 1998). A construção desses sentidos parece não se limitar às representações apenas de Blumenau ou do Vale. Mesmo porque Blumenau não é o único lugar do Estado a reverenciar traços da cultura europeia e festejar o culto aos colonizadores provenientes da Europa. Por ser considerada polo de uma região e sinônimo de germanidade, com alcance na imprensa internacional, Blumenau assume centralidade neste estudo pelas especificidades apresentadas. Mas as reflexões aqui expressas ultrapassam os limites do município: contribuem para pensar as relações entre jornalismo e uma identidade dominante na própria noção criada em torno de toda uma região identificada como Sul do Brasil.

Em Blumenau, a exaltação do passado e a idealização da memória assinalam a característica identitária, conforme diversos estudos apontam desde os anos 1990 (MACHADO, 2011; VOIGT, 2008; FROTSCHER, 2007; 1998; FLORES, 1997). A criação de uma imagem engessada segue presente em discursos comemorativos, monumentos institucionais, e se reflete nas ações em torno do mito fundador da cidade. Embora a formação histórica do município ganhe destaque pela imigração europeia, 
era ocupada por famílias ${ }^{6}$, inclusive por indígenas Kaigangs e Xocklengs, além de africanos escravizados, antes da chegada dos 17 imigrantes à colônia. O genocídio indígena no Vale tem sido tratado em estudos recentes, mas, em termos de símbolos oficiais permanece ignorado, com a omissão sobre sua existência. Assim como a presença de escravos na região, a herança indígena tem pouca visibilidade nas páginas do jornal estudado no período em questão. Como se não houvesse lugar para a cidade alemã também se considerar negra ou indígena.

Não se pode, nem se pretende negar: a colonização teve forte influência germânica em Blumenau, com impacto direto inclusive na imprensa local. Os primeiros jornais nasceram em língua alemã. O primeiro, Blumenauer Zeitung, lançado em 1881, foi seguido por Immigrant e Der Urwaldsbote, que assumiu posturas xenófobas e racistas, sendo considerado o "mais pangermanista" dos jornais (FROTSCHER, 1998). Somente em 1924, com A Cidade, passaria a circular o primeiro jornal em língua portuguesa em Blumenau. A consolidação da imprensa como atividade industrial também permitiu momentos de questionamento desta narrativa, conforme apontou a análise do JSC. No entanto, narrativas predominantes insistem em atribuir a prosperidade da colônia alemã ao "passado pioneiro", além de outros "elementos simbólicos de distinção" (SEYFERTH, 2012), reproduzidos e reelaborados pela cobertura jornalística a cada nova edição da festa.

Não por acaso um dos entrevistados para a pesquisa, o ex-presidente do Parque Vila Germânica, Norberto Mette (2015), que por mais tempo esteve à frente da Oktoberfest e a quem se atribui o título de "salvador de uma tradição"7, conta: "[...] Eu tinha desde o início a preocupação de apresentar novidades. Até por que, a primeira coisa que o pessoal da imprensa queria saber era: 'qual a novidade da festa este ano?'” (METTE, 2015). O depoimento reforça a característica imposta pelo ritmo do trabalho jornalístico, o culto ao imediatismo (já que a notícia salienta a novidade da informação como princípio) e a ênfase nos acontecimentos e não nas problemáticas dos fatos narrados (TRAQUINA, 1999; 2005). A implantação dessas "novidades" no caso da festa de Blumenau inclui ampliação do cardápio, por exemplo, desde que o novo item tenha relação direta com a Alemanha.

6 Segundo a historiadora Sueli Petry, do Arquivo Histórico de Blumenau, em entrevista à autora em 2015. 7 Como aparece no texto publicado no site de notícias Blumenews, cujo título é Noberto Mette - o homem que salvou uma tradição. Disponível em: http://antigo.blumenews.com.br/index.php/capa/item/1779-norberto-metteohomem-que-salvou-uma-tradi\%C3\%A7\%C3\%A3o. Acesso em: 23 mar. 2016. 
A versão consagrada pelas páginas da imprensa, que parece não reconhecer a participação de outros grupos étnicos na composição do município nas últimas décadas, ganha impulso com a invenção da cidade alemã. A partir dos anos 1960, surgem as políticas públicas e investimentos na germanidade como elemento identitário distintivo. É desse período, especificamente setembro de 1968, a campanha de divulgação precursora em âmbito nacional na associação de Blumenau à "Europa Brasileira". O encarte especial ocupou oito páginas da revista Seleções Reader's Digest, uma das mais populares à época, e lançava o slogan: "Adivinhe que país é êste"8 (sic).

Assim como as campanhas publicitárias do poder público municipal, a Oktoberfest também se configura como elemento importante neste cenário de germanização. A primeira edição da festa ocorreu em 1984, "quase uma repetição do que havia acontecido em janeiro do mesmo ano na vizinha Pomerode - uma festa para mostrar ao país a 'cidade mais alemã do Brasil', chegando a surpreender os seus organizadores com o sucesso" (FLORES, 1997, p. 162). Difundida como indicativo da capacidade de superação da população pós-enchente, a festa ultrapassou fronteiras na divulgação do município. É citada de forma recorrente como marca de orgulho e identidade coletiva e resulta dos esforços em manter uma representação ligada à tradição e ao trabalho. A pesquisadora Méri Frotscher estudou a relação entre etnicidade e o trabalho com foco em Blumenau na sua dissertação de mestrado, ampliando olhares e possibilidades de pensar o município: "O governo municipal fez largo uso da germanidade para mostrar uma cidade habitada por um povo ordeiro e trabalhador" (FROTSCHER, 1998, p. 3).

A constatação observada por Frotscher (1998) se apresenta em diferentes percepções mais de 20 anos depois de seu estudo: "É outro país dentro do Brasil", definem os turistas, entusiasmados. "Trata-se da Europa brasileira", sustenta o marketing turístico. "Bem-vindos ao Vale Europeu", saúdam as placas indicativas institucionais. Campanhas recentes $^{9}$ lançadas pela prefeitura mostram que a tentativa de forçar uma

\footnotetext{
8 Apresentava fotos de casas típicas, sugerindo que se tratasse de algum país europeu, até revelar: "Sim, é Brasil. Você pode conhecer um outro país sem deixar a sua terra, sem dólares, sem passaporte. É só tomar o caminho de Blumenau".

9 Os discursos exaltados em favor da germanidade em Blumenau ganharam força novamente em 2014, quando a prefeitura lançou o slogan: "Blumenau - Alemanha sem passaporte" (Figura 3), com a finalidade de atrair turistas. Em 2015, a prefeitura ignorou as reações contrárias e reforçou a marca com a campanha "Blumenau - o Brasil de alma alemã".
} 
imagem alemã de Blumenau não é prática restrita ao passado, mas recorrente. Um dos pilares deste pensamento na busca pela tentativa de "diferenciar" a região está no pensamento de um "Vale Encantado", pois europeu. A ideia de que o município, assim como a região, distingue-se pela herança de seus colonizadores europeus, sobretudo "alemães", vincula-se à noção de uma cultura pretensamente superior, ao pertencimento de outra nacionalidade, diferente da brasileira. Pesquisadores já se debruçaram sobre o fenômeno da germanidade em Blumenau, nas áreas da História, Literatura e Arquitetura, citando apenas três delas. Faltam, no entanto, estudos que aprofundem a questão na interface com o campo do Jornalismo.

\section{Jornalismo e germanidade: a construção de uma narrativa dominante}

Este trabalho está alinhado com a perspectiva que entende o jornalismo como forma social de conhecimento (GENRO FILHO, 2012). Apesar de ter nascido junto com os meios industriais de amplificação da informação, "[...] possui características próprias enquanto forma de conhecimento social e ultrapassa, por sua potencialidade histórica concretamente colocada, a mera funcionalidade ao sistema capitalista" (GENRO FILHO, 2012, p. 42). A contribuição de um dos precursores da teoria do jornalismo no Brasil possibilita compreender o jornalismo informativo como resultado de uma necessidade social, o que the permitia enfrentar críticas de que a profissão atenderia apenas aos interesses da burguesia ou estaria a serviço da alienação. Seus pressupostos teóricos contribuíram na desconstrução do entendimento da atividade jornalística reduzida à técnica, contemplando-a como potencial de transformação social.

A germanização de Blumenau alcança também o jornalismo, cujo papel seria problematizar essas questões: mais suspeitando das identidades que parecem ser únicas, universalizantes e generalistas, do que chancelando os mitos fundadores e identitários. Mas uma aparente trajetória histórica do que seria o "passado de Blumenau" tem sido regularmente apropriada pela imprensa como parte relevante dos processos de legitimação dessa identidade. A reverência à cultura dos imigrantes de 
origem germânica passou a ser explorada de forma a projetar Blumenau no contexto nacional. Em momentos de forte simbolismo, como na Oktoberfest, este tipo de cobertura se torna ainda mais notória. O argumento repetido por jornalistas locais de que esta seria a única oportunidade para Blumenau ganhar as páginas da grande imprensa ou minutos em rede nacional de televisão, por exemplo, parece dizer muito acerca da compreensão sobre o Jornalismo e a necessidade de repensá-lo.

A cidade pode vencer sua dependência de associação direta à germanidade para se tornar pauta nacional. Esta apropriação pelo jornalismo de mecanismos e jargões utilizados pelo marketing turístico e pela propaganda da festa também foi algo estimulador à investigação. Alguns discursos têm sido recorrentes, impondo um modelo de abordar a cidade, legitimado pela agenda midiática dominante. Em geral, apelos lançados pela publicidade, tais como festa mais alemã do Brasil, pedaço da Europa no Brasil ou Alemanha Brasileira, tornaram-se clichês estimulados e reproduzidos pela imprensa. A tendência da implantação de um pensamento limitado por estas versões desafia o papel jornalístico e diminui as possibilidades de novas interpretações. Reduzido a ser reprodutor da voz oficial ou pautado por interesses meramente comerciais, o jornalismo se arrisca a perder a sua capacidade concreta de informação e transformação.

Como metodologia desta pesquisa, buscamos amparo na análise crítica da narrativa, proposta por Luiz Gonzaga Motta (2013). A partir da amostragem, procuramos identificar as etapas sugeridas por Motta na construção deste processo. Além do material empírico, os procedimentos metodológicos se apoiaram em 23 entrevistas com pessoas reconhecidas pela atuação pública em favor da germanidade ou contrárias à narrativa hegemônica em Blumenau, e jornalistas que atuaram no JSC. A realização de entrevistas em profundidade (Duarte, 2006) ampliou a massa documental para análise e foi considerada necessária por evidenciar o embate pela hegemonia, apontar atores sociais relevantes no debate e conhecer argumentos utilizados. Além disso, os depoimentos permitiram acessar informações e contextos não revelados pela análise das reportagens. A seleção das pessoas entrevistadas ocorreu com base em abordagem temática do corpus.

A necessidade de o município querer ser Alemanha deve ser questionada de forma periódica porque tal concepção é também renovada constantemente. Em Blumenau, a busca por uma afirmação fora de si e 
da diversidade que a constitui soa uma dificuldade de assumir a si própria. Teóricos dos estudos identitários entendem a identidade como dinâmica, portanto, condicionada a transformações, em processo social continuado, permanente (HALL, 2003; SANTOS, 1994). O investimento no reforço da identidade alemã parece surgir com maior relevância em resposta alternativa à crise do setor têxtil nos anos 1980. Sabe-se da recorrência à identidade nos momentos de crise, e em Blumenau não parece ser diferente. O município costuma aparecer em diferentes contextos, como se seus resultados fossem explicados devido à presença de alemães. Seus dinamismos, desempenhos e êxitos refletiriam a germanidade e apenas ela (HERING, 1987).

É necessário questionar se e, principalmente, como e por que o jornalismo colabora e impulsiona a legitimação dessa representação germânica de Blumenau. Seria o jornalismo capaz de não se reduzir à reprodução desse discurso, mas provocar reflexões críticas acerca do fenômeno? Não há dúvidas de que sim, amparando-se no modo de conceber a atividade jornalística a partir do pensamento de Genro Filho (2012). Mas, é preciso reconhecer: ainda há uma larga margem para a imprensa deixar de chancelar aspectos simplórios germanófilos e fazer contrapontos, representar mais a diversidade que a cidade possui. Esse processo requer pensar sobre as finalidades esperadas e atribuídas ao jornalismo (REGINATTO, 2019). Um dos motivos da importância de estudar o campo é compreender sua contribuição na construção social da realidade (BERGER; Luckmann, 1973). A atividade se estabelece como intermediadora de sentidos por fornecer fragmentos de referências e explicações do mundo.

O JSC assume a voz de narrador principal nesta pesquisa não por acaso. Foi um dos primeiros diários com abrangência por todas as regiões de Santa Catarina, até focar sua cobertura em Blumenau e região, após a aquisição pela RBS, em 1992. Não há como desconsiderar sua representatividade como uma espécie de "mediador" do debate público. Mas, sabendo que a germanização é uma prática não exclusiva do periódico, colocamos em discussão aqui um modelo jornalístico. O jornalismo assume espaço importante como produtor de narrativas que interferem e conduzem nas leituras de mundo, cotidianamente, desenvolvidas pelos próprios indivíduos e assimiladas por eles. Por isso, configura-se como um dos elementos indiscutíveis da engrenagem que 
cria noções do real. No caso da hegemonia germânica em Blumenau, identificamos vários agentes atuantes no processo. A imprensa é um deles, mas não age sozinha ou isoladamente (MEDITSCH, 2010).

\section{A análise nas páginas do JSC}

A seleção dos materiais de análise compreendeu as edições do Jornal de Santa Catarina (JSC) no período de janeiro de 1984 a dezembro de 2015, considerando o ano de lançamento da primeira edição da Oktoberfest. O corpus foi escolhido com base em estudo exploratório temático, ao qual se submeteu à análise crítica da narrativa. Reuniu 30 reportagens; em 15 delas a ênfase está no reforço à germanidade e, nas outras 15, na abertura ao questionamento da identidade predominante. Classificamos as primeiras como germanófilas e as segundas como plurais. Como material de apoio, consideramos ainda cadernos especiais de aniversário de Blumenau durante o período, feitos pelo JSC. Apesar do predomínio de abordagens germanófilas, os questionamentos contra-hegemônicos demonstraram a existência de uma disputa pela narrativa oficial da cidade, confirmada pelas entrevistas com os agentes sociais envolvidos.

As análises das páginas do JSC no período de 31 anos reforçaram a existência de um confronto sobre a identidade de Blumenau. Esta contradição de ideias se revela nas vozes de quem requer a germanidade como forma de marcar diferença em contraponto aos discursos questionadores dessa construção, cuja defesa é pelo reconhecimento da pluralidade. Diante da impossibilidade de analisar as 30 reportagens contempladas na pesquisa neste artigo, limitamo-nos aqui com mais detalhes apenas a uma delas, intitulada: Pesquisa de opinião coloca em xeque a tradição alemã, (PESQUISA, 1990, p. 20). A escolha por esta matéria segue um dos passos indicados por Motta (2013) na metodologia criada pelo autor, especialmente no que se refere ao "movimento de identificação de conflitos" pois a reportagem em questão demonstra a existência de uma contra-hegemonia ao discurso dominante.

Esta narrativa aparece no levantamento sobre tradição, feito pelos alunos da Escola Técnica do Vale do Itajaí (ETEVI) com professores e alunos da Universidade Regional de Blumenau (FURB), cujos resultados 
foram considerados "surpreendentes e contraditórios". Se, por um lado, 85,66\% dos entrevistados defendeu o cultivo às tradições germânicas; $66,8 \%$ desse mesmo universo alega não desenvolver qualquer ação para cultivar alguma tradição. Chama ainda mais atenção o fato de o texto ter sido publicado em página inteira do formato standard, portanto, com amplo espaço ao debate. A foto central é do Castelinho da antiga loja Moellmann, símbolo frequente associado ao município e também usado como imagem que remete à noção de Sul do Brasil. A reportagem repercutiu os resultados, com depoimentos e opiniões de quatro professores da FURB. Entre eles, o professor aposentado doutor em Letras da instituição, José Endoença Martins, também entrevistado para esta pesquisa. Ele foi autor do pensamento mais incisivo na discussão publicizada pelo jornal à época. Apresentou um olhar sobre as tradições germânicas e a Oktoberfest dificilmente observado na cobertura do JSC ao longo das 31 edições da festa. Segundo ele:

A indiferença e respostas contraditórias mostram o que é realmente esta tradição, o que é a Oktoberfest: uma comercialização, onde só se beneficia quem tem algo a vender. Claro que alguns se divertem, mas não existe preocupação em discutir cultura. É um espaço carnavalizado. Quanto ao resultado que a festa é para turistas, não é somente isso. Ela é principalmente uma paganização da vida, do cotidiano. É o poder econômico decidindo que tipo de prazer as pessoas devem ter (Jornal de Santa Catarina, 30 de outubro de 1990, p. 20)

Esta reportagem se apresenta como simbólica também porque a visibilidade a vozes contraditórias à festa se manteve com pouco destaque na cobertura jornalística do principal jornal de Blumenau e região no período analisado. Em entrevista para esta pesquisa, Endoença Martins, que é membro do Núcleo de Estudos Afrobrasileiros (NEAB/ FURB), defendeu que a pluralidade resultará de um movimento externo, "que provocará uma brecha na germanidade local, forçando-a abrir-se e a impregnar-se de outras culturas" (MARTINS, 2016). Ele disse acreditar que Blumenau "não tem as condições necessárias para fazer uma ruptura consigo mesmo, uma vez que optou pela singularidade. [...] A pluralidade que se deseja virá de fora, como uma ação de implosão de 'o alemânico espírito'” (MARTINS, 2016). A problematização da identidade de Blumenau também aparece na pauta do JSC, embora em menor destaque. 
Se a primeira impressão pode ser a de que o JSC tenha apenas contribuído para fortalecer a identidade germânica, um olhar mais apurado revela, também, a abertura pontual de espaço ao contraditório no periódico. Embora o conteúdo a favor da identidade hegemônica seja mais intenso, em situações específicas o jornal também questionou a ideia predominante. Para citar alguns exemplos, esta problematização ocorreu por meio de discussão sobre o incentivo ao falso enxaimel ${ }^{10}$, a participação da população negra na história do município ou a organização de outros movimentos culturais no município, como o carnaval popular. Na contramão, os textos que reduzem a visão de Blumenau à "terra de alemães" (germanófilas) utilizam-se de estratégias argumentativas no reforço à preservação das tradições, valores como o trabalho e a comparação direta com a Alemanha de modo repetitivo e caricatural.

A ausência do contraditório se verifica como marca das narrativas germanófilas. No entanto, ao propor novos olhares sobre a realidade e ousar leituras contrapostas à visão hegemônica, por meio das reportagens classificadas como plurais, o jornal também mostra as potencialidades jornalísticas, como instrumento de transformação. Embora esta postura assumida pelo JSC leve a crer que o jornal estaria permitindo esses novos olhares apenas para conferir algum grau (mínimo) de credibilidade ao seu discurso editorial (que defende a pluralidade) e forçar ainda mais a legitimidade da imposição germânica. Não seria este um álibi para afirmar com maior eficácia a germanidade em Blumenau? Acreditamos que sim. O JSC, como a maioria dos jornais, utiliza-se da imparcialidade como valor para legitimar a realidade. O contrato social de verdade estabelecido com o leitor depende de elementos que tornem a sua narrativa a mais verossímil possível (MOTTA, 2013).

A atividade jornalística pressupõe características próprias e valores legitimados pelo campo, como a apresentação de pontos de vista diferentes, promoção do debate de ideias contraditórias e o confronto de versões. Mas, a reprodução de um discurso sem problematizá-lo provoca distorções conflitantes com os próprios princípios elementares e basilares da profissão (KOVACH; ROSENSTIEL, 2003; REGINATTO, 2019).

\footnotetext{
100 enxaimel, também conhecido como Fachwerk, em alemão, caracteriza-se como estrutura de uma edificação feita de elementos de madeira encaixados, formando um conjunto inteiro e único, cujos vãos podem ser preenchidos com paredes de diferentes materiais. Tal técnica construtiva apresenta "uma das expressões culturais máximas - na forma de arquitetura" da Alemanha (WITTMANN, 2019, p. 368). Em função das condições encontradas no Vale do Itajaí, e também em outras regiões do Brasil, foi usada por imigrantes e descendentes, influenciando a arquitetura dos colonos alemães.
} 
Ao reportar o distante, as narrativas jornalísticas abusam de generalizações, baseiam-se em identidades reducionistas. Geram, portanto, uma simplificação que limita a representação no imaginário social. Mas, como se pôde perceber a partir da pesquisa, muitas vezes essas generalizações ocorrem pela própria imprensa local e, sem contraponto, ganham legitimidade.

O corpus analisado indica que as temáticas apresentadas pelas forças contra-hegemônicas ganham as páginas do JSC, principalmente, quando partem da iniciativa de terceiros. Não costumam, portanto, ser voz do próprio jornal, mas voz permitida no jornal, sendo consequência do trabalho de investigação de pesquisadores, intelectuais ou entidades específicas. Parecem ser pauta no jornal quando não há como ficar indiferente a ela; ou não se quer deixar de noticiar sob o risco de conquistar visibilidade em outros veículos de comunicação, perdendo uma possível audiência. Assim, o JSC passa a ser um narrador do "germano espírito", às vezes de modo sutil, noutros momentos, nem tanto. As questões ligadas à Oktoberfest aparecem com amplo destaque no periódico durante todo o ano, não apenas no mês de outubro quando podem ganhar uma contagem regressiva na capa, numa demonstração de como a festa pauta e influencia o jornal.

Os cadernos especiais produzidos pelo JSC para o aniversário de Blumenau reúnem a repetição de marcas discursivas, como o apelo a estereótipos e enunciados clicherizados, por isso incluídos na análise. Termos "heróis" e "desbravadores" aparecem de forma recorrente nas atribuições aos colonizadores alemães - tratamento curioso, sobretudo quando comparado à cobertura sobre novos imigrantes, especialmente haitianos, sem o mesmo tom de exaltação. A narrativa nos suplementos comemorativos é construída de modo a exaltar valores atribuídos à colonização germânica a começar pela data escolhida para a celebração do aniversário (2 de setembro, que marcaria a vinda dos imigrantes europeus em 1850. Enquanto a data de emancipação da colônia e transformação em município, em 18 de março de 1882 costuma ser ignorada). É como se a cidade quisesse sair do mapa do Brasil e assumir uma ideia de nação própria.

As reportagens de valorização da identidade germânica de Blumenau não se restringem a uma editoria específica. Elas aparecem diluídas em coberturas que naturalizam a imagem do município como 
"Alemanha Brasileira". Do caderno de Turismo à editoria de Política, sustentam-se em símbolos como a gastronomia, a arquitetura e valores como o trabalho e as atividades dos clubes de caça e tiro. Palavras sinônimas de tradição e valorização do passado aparecem neste contexto frequentemente. Os textos também se valem de comparações simplórias do tipo "Alemanha é aqui", sugerindo que Blumenau reproduz, na sua integridade, o modo de vida, os costumes e hábitos do país europeu. Embora submetido à época ao Guia de Ética da RBS, tendo como pressuposto a busca pela pluralidade de versões e pela diversidade; no caso da identidade de Blumenau não é isso que identificamos.

O último texto presente na amostragem de reportagens germanófilas corrobora a afirmação. A capa da edição do JSC de 16 de outubro de 2015 apresenta a manchete: Como se vestir para a Oktober. Na frase complementar, há a tentativa de explicar o injustificável: "Se você não vai de traje típico, confira as dicas de peças mais adequadas ao seu jeito de curtir a festa: em família com os amigos, para dançar ou para quem está mais interessado em comer". Não bastasse a fragilidade do tema, tratado como assunto mais importante da edição, e por isto exposto na forma de manchete, a associação à foto principal (uma mãe com uma criança nos braços, vítimas de enxurrada na noite anterior, conforme imagem a seguir - Figura 1) gerou mal-estar e reações nas redes. Mesmo que não intencional, a abordagem faz pensar inevitavelmente sobre critérios para a pauta jornalística no veículo e imaginário social de jornalistas da redação. 
Figura 1 - Capa JSC edição de 16 de outubro de 2015

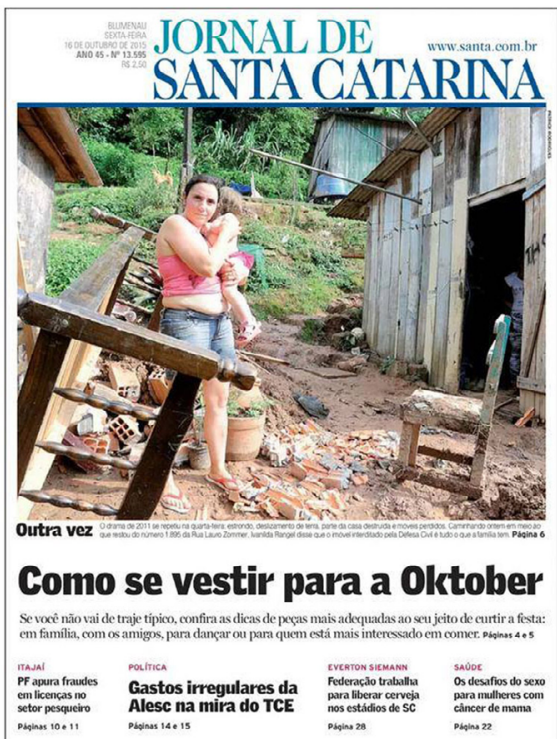

Fonte: Reprodução/ Jornal de Santa Catarina.

Figura 2 - Cartaz oficial da Oktoberfest 2016, com apologia ao culto às tradições

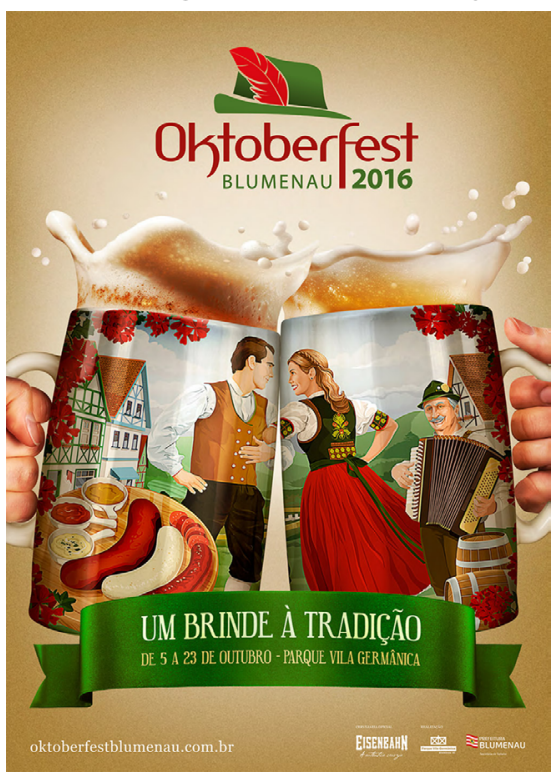


Figura 3 - Campanha lançada pela prefeitura em 2015. Blumenau: Alemanha sem passaporte

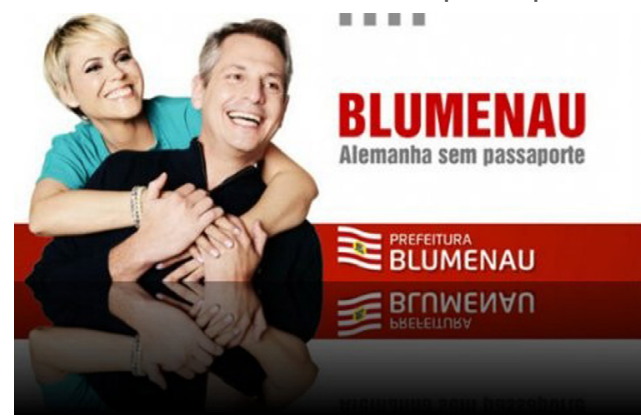

\section{Considerações finais}

O entendimento de que o jornalismo produz e constrói a realidade é comum em diferentes campos do conhecimento. A partir dos anos 1970 ganharam evidência as pesquisas voltadas à análise dos efeitos das mensagens jornalísticas sobre o público e a construção da realidade pelo discurso jornalístico. Embora não tratem especificamente do jornalismo, Berger e Luckmann (1973) influenciaram essas noções. Para eles, a realidade é construída socialmente. O jornalismo se estabelece como intermediador de sentidos por fornecer fragmentos de referências e explicações do mundo. Desempenha papel central na mediação das pessoas com a realidade, ao organizar o debate público das questões de interesse coletivo. Apesar de ser confundido com o real, representa apenas um recorte da construção do real.

O não dito do discurso e o fundo ideológico sinalizam sentidos e, também, legitimam as narrativas em torno da germanidade de Blumenau. Uma das metanarrativas (MOTTA, 2013) presentes neste debate está subentendida na ideia eurocentrista. Esta concepção permeia as narrativas predominantes: reconhecemos a cultura alemã como superior e condenamos as demais à subalternização do silêncio ou apagamento. Ao naturalizar o discurso e reproduzir essa narrativa, a imprensa reforça um estereótipo, ignora seu potencial de transformação e o direito ao contraditório, condição básica e fundamental de toda mídia democrática. 
O jornalismo constitui uma força poderosa nesta engrenagem, especialmente pelo alcance, influência e credibilidade e mais ainda por carregar potencial legitimador de ideias estabelecidas. Contudo, não se pode correr o risco de sobrevalorizar seu papel no fenômeno como único responsável por essa constituição. Também seria um erro subestimar a recepção do público, atribuindo-Ihe condição de passividade. Os veículos de comunicação podem induzir uma identidade predominante de Blumenau, simbolicamente personificada na imagem do Fritz, com chapéu alemão e chope na mão ou na noção de povo ligado à tradição germânica, superação e trabalho. No entanto, uma parcela expressiva dos receptores não está aprisionada a esta significação alienante, tendo condições de não assimilar a visão imposta como hegemônica, recusar e contrapor-se à versão, a partir de mecanismos como a relação estabelecida com a realidade referida e o acesso a outras narrativas sobre a temática.

Enxergar a imprensa como único elemento ou mesmo principal ator na construção social da realidade é um equívoco. Estamos de acordo com a visão de que o jornalismo participa da produção da realidade, mas não se pode atribuir apenas a ele esta responsabilidade. Seria ingenuidade, além de subestimar a audiência e anular a capacidade crítica do público receptor. Reconhecemos, entretanto que, embora não seja o único agente, o jornalismo desempenha papel importante nesta relação, não podendo, portanto, ser ignorado, pois não é capaz de determinar o pensamento coletivo, mas colabora para formar consensos.

Se quem narra está sempre imbuído de motivação ou propósito específico e nenhuma narrativa é ingênua, neutra ou imparcial (MOTTA, 2013), qual é a intencionalidade do narrador ao sustentar a exaltação germânica como característica natural de Blumenau? Quando negamos a diversidade de Blumenau, insistimos na representação dominante desde a fundação da colônia, que apaga a contribuição de negros, indígenas e todos aqueles vistos como "desviantes" da norma imposta pelo rótulo europeizante. O não enfrentamento da versão hegemônica pela imprensa conserva uma imagem distante da contemporaneidade, ancorada num passado obsoleto e apegada a um discurso marcado por intencionalidades. Por trás da defesa obsessiva pela manutenção da identidade alemã de Blumenau, esconde-se o mito da superioridade branca e o etnocentrismo cultural. O uso da imprensa na manutenção 
deste pensamento reforça a disseminação de preconceitos e demonstra o não cumprimento das potencialidades do jornalismo a favor da pluralidade humana.

\section{REFERÊNCIAS}

BERGER, Peter L; LUCKMANN, Thomas. A construção social da realidade: tratado de sociologia do conhecimento. Petrópolis: Vozes, 1973.

DUARTE, Jorge. Entrevista em profundidade. In: DUARTE, Jorge; BARROS, Antonio (org.). Métodos e técnicas de pesquisa em comunicação. São Paulo: Atlas, 2006.

FOUCAULT, Michel. A arqueologia do saber. 2. ed. Rio de Janeiro: Forence Universitária, 1986.

FLORES, Maria Bernardete Ramos. Oktoberfest: turismo, festa e cultura na estação do chopp. Florianópolis: Letras Contemporâneas, 1997.

FROTSCHER, Méri. Etnicidade e trabalho alemão. Outros usos e outros produtos do labor humano. Dissertação (Mestrado em História) - Programa de Pós-Graduação em História, Centro de Filosofia e Ciências Humanas, Universidade Federal de Santa Catarina, Florianópolis, 1998. Disponível em: https://repositorio.ufsc.br/xmlui/handle/123456789/77817. Acesso em: 23 de mar. 2020.

FROTSCHER, Méri. Lobo em pele de Cordeiro: ideário nacional-socialista no material de entretenimento do Blumenauer Volkskalender (1933-1938). Blumenau em Cadernos. Tomo XLVIII - nov./ dez. 2007. (Edição especial 50 anos)

FROTSCHER, Méri. Identidades Móveis: Práticas e discursos das elites de Blumenau (19291950) Blumenau: Edifurb, 2007.

GENRO FILHO, Adelmo. O segredo da pirâmide. Para uma teoria marxista do jornalismo. Florianópolis: Editora Insular, 2012.

HALL, Stuart. A identidade cultural na pós-modernidade; tradução de Tomaz Tadeu da Silva, Guaracira Lopes Louro. 7. ed. Rio de Janeiro: DP\&A, 2003.

HERING, Maria Luiza Renaux. Colonização e indústria no Vale do Itajaí: $\bigcirc$ modelo catarinense de desenvolvimento. Blumenau: Editora da FURB, 1987.

KOVACH, Bill; ROSENSTIEL, Tom. Os Elementos do Jornalismo: o que os jornalistas devem saber e o público exigir. Geração Editorial: São Paulo, 2003.

Pesquisa de opinião coloca em xeque a tradição alemã. Jornal de Santa Catarina. Blumenau, ano 19, 30 out. 1990 , p. 20.

Editorial. Jornal de Santa Catarina. Blumenau, ano 1, n. 1, 22 de setembro de 1971, p. 2.

Como se vestir para a Oktober. Jornal de Santa Catarina. Blumenau, ano 44. 16 de outubro de 2015, p. 1. 
MACHADO, Ricardo. A invenção da cidade etnizada: história e memória na Blumenau contemporânea (1974-2002). Anais do XXVI Simpósio Nacional de História - ANPUH. São Paulo, julho 2011.

MARTINS, José Endoença. [26 mar. 2016]. Entrevistadora: Magali Moser. Blumenau, 2016. Por email. MEDITSCH, Eduardo. Jornalismo e construção social do acontecimento. In: BENETTI, Márcia e FONSECA, Virginia Pradelina da Silveira (Orgs). Jornalismo e Acontecimento: mapeamentos críticos. Florianópolis: Insular, 2010.

METTE, Norberto. [17 out. 2015] Entrevistadora: Magali Moser. Blumenau, 2015. Gravação em arquivo mp3.

MOSER, Magali. Jornalismo forjado: A participação da imprensa na imposição da identidade germânica em Blumenau. 2016. 350p. Dissertação (Mestrado em Jornalismo) - Programa de Pós-Graduação em Jornalismo, Universidade Federal de Santa Catarina, Florianópolis, 2016.

MOTTA, Luiz Gonzaga. Análise Pragmática da narrativa jornalística. In: LAGO, Claudia; BENETTI, Marcia. Metodologia de pesquisa em jornalismo. Petrópolis: Vozes, 2007.

MOTTA, Luiz Gonzaga. Análise crítica da narrativa. Brasília: Editora Universidade de Brasília, 2013.

REGINATTO, Gisele Dotto. As finalidades do jornalismo. Florianópolis: Insular, 2019.

SANTOS, Boaventura de Sousa. Modernidade, identidade e a cultura da fronteira. Tempo Social. Ver. Sociol. São Paulo: USP, 1994.

SEYFERTH, Giralda. Memória Coletiva, Identidade e Colonização: representações da diferença cultural no Sul do Brasil. Revista MÉTIS: história \& cultura. Programa de Pós-Graduação em História - UCS. Caxias do Sul, RS: Educs, jul./dez. 2012, p. 13-39.

TRAQUINA, Nelson. Teorias do jornalismo: porque as notícias são como são. Florianópolis: Insular, 2005.

TRAQUINA, Nelson (org.). Jornalismo: questões, teorias e "estórias". Lisboa: Vega, 1999.

VOIGT, André Fabiano. Imigrantes entre a e cruz e a espada: imigração alemã, confissão religiosa e cidadania no Vale do Itajaí (1847-1863).1999. Dissertação (Mestrado em História) - Programa de Pós-Graduação em História, Centro de Filosofia e Ciências Humanas, Universidade Federal de Santa Catarina, Florianópolis, 1999.

VOIGT, André Fabiano. A invenção do Teuto-brasileiro. 2008. Tese (Doutorado em História Cultural) - Programa de Pós-Graduação em História, Centro de Filosofia e Ciências Humanas, Universidade Federal de Santa Catarina, Florianópolis, 2008.

WITTMANN, Angelina. Fachwerk: A técnica construtiva enxaimel. Blumenau: AmoLer Editora, 2019. 


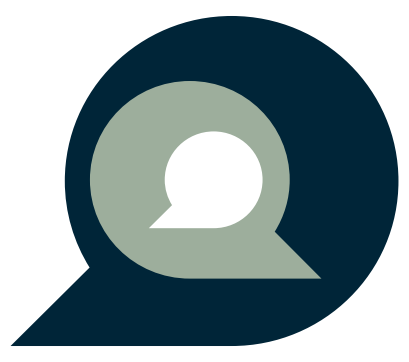

